\title{
Ação dos aditivos estabilizador de hidratação e incorporador de ar em pastas de cimento Portland
}

\author{
Action of hydration stabilising admixture and air- \\ entrained admixture in Portland cement pastes
}

\section{Juliana Pippi Antoniazzi \\ Gihad Mohamad \\ Juliana Machado Casali \\ Raquel Petry Brondani Schmidt \\ Bernardete Trindade}

\section{Resumo \\ A}

argamassa estabilizada é uma mistura pronta que contém os aditivos incorporador de ar (AIA) e estabilizador de hidratação (AEH) em sua composição a fim de aumentar sua trabalhabilidade e o período de aplicação por até $72 \mathrm{~h}$. O trabalho avaliou a ação desses aditivos em pastas de cimento Portland, empregados isoladamente e combinados, desprezandose o efeito do agregado. No estado fresco foram determinadas viscosidade, densidade de massa, ar incorporado e tempo de pega. Foram avaliadas no estado endurecido capilaridade, densidade de massa e resistência mecânica. Os resultados demonstraram interferência e ação cruzada de efeitos entre os aditivos, demonstrando que o AEH também pode incorporar ar às pastas e que o AIA pode causar retardo no tempo de pega. A viscosidade demonstrou ter relação com a estabilidade das bolhas incorporadas, e não com o teor de ar. O AEH proporcionou maior fluxo de água por capilares, contrariamente ao AIA. A resistência mecânica das pastas com altos teores de AEH sofreu redução, indicando possível retardo na formação de compostos hidratados. Os teores intermediários de AEH demostraram ser mais adequados para misturas estabilizadas de cimento, podendo ser associados a teores mais elevados de AIA sem comprometer suas propriedades.

'Juliana Pippi Antoniazzi Universidade Federal de Santa Maria Santa Maria - RS - Brasil

${ }^{2}$ Gihad Mohamad ${ }^{2}$ Universidade Federal de Santa Maria Santa Maria - RS - Brasil

${ }^{3}$ Juliana Machado Casali ${ }^{3}$ Instituto Federal de Santa Catarina Florianópolis - SC - Brasil

${ }^{4}$ Raquel Petry Brondani Schmidt ${ }^{4}$ Universidade Federal de Santa Maria Santa Maria - RS - Brasil

${ }^{5}$ Bernardete Trindade ${ }^{5}$ Universidade Federal de Santa Maria Santa Maria - RS - Brasil

Recebido em 04/09/19 Aceito em 25/03/20
Palavras-chave: Aditivo estabilizador de hidratação. Aditivo incorporador de ar. Pasta de cimento Portland.

\section{Abstract}

Ready-mix mortar is a ready-to-use mix containing air-entrained admixture (AEA) and hydration stabilising admixture (HSA) in its composition in order to increase workability and application time by up to 72 hours. This study evaluated the action of these admixtures in Portland cement pastes, employed bothalone and in combination, isolating the aggregate'seffect.The properties of viscosity, specific gravity, entrained air and setting time were assessed in the freshstate. In the hardenedstate, capillarity, specific gravity and mechanical strength were evaluated. The results demonstrated interference and cross action between the admixtures, showing that HSA can also incorporate air into the paste and that AEA can delay setting time. Viscosity proved to be related to thestability of incorporated bubbles, but not to air content. The AEH provided greater capillarywater flow, unlike the AIA. The mechanical strength of high content hydration stabilising admixture pastes decreased sharply, indicating possible delay in the formation of hydrated compounds. The intermediate AEH contents show to be more suitable for ready mix cement, which can be associated with higher AIA contents, without compromising its properties.

Keywords: Hydration stabilising admixture. Air-entrained admixture. Portland cement paste. 


\section{Introdução}

O emprego das argamassas usinadas no Brasil teve início na década de 1980 e desde então vem ganhando espaço no mercado da construção civil, mais expressivamente nos últimos anos. As argamassas estabilizadas são misturas industrializadas que chegam à obra prontas para ser utilizadas, mantendo suas propriedades por até $72 \mathrm{~h}$, o que proporciona maior agilidade aos sistemas construtivos.

Para atender a essas condições, as argamassas estabilizadas têm em sua composição aditivos químicos que modificam suas características reológicas, conferindo-lhes maior trabalhabilidade e tempo de utilização. Assim, são empregados, além do cimento, agregado miúdo e água, um aditivo incorporador de ar (AIA), responsável pela melhora na trabalhabilidade da argamassa no estado fresco, e um aditivo estabilizador de hidratação (AEH), o qual aumenta o tempo de trabalhabilidade da mistura.

Os AIA são compostos químicos orgânicos pertencentes à classe dos tensoativos, geralmente de caráter aniônico, constituídos de uma extremidade hidrofóbica (apolar) e outra hidrofílica (polar). Assim, agem diminuindo a tensão superficial da mistura, proporcionando a incorporação de microbolhas de ar, compressíveis e estáveis, quando submetidos à agitação mecânica. Essas bolhas de ar são carregadas negativamente, o que as mantém afastadas entre si e proporciona a união entre as partículas de cimento devido à atração de cargas opostas, dando maior coesão ao sistema (RAMACHANDRAN, 1984; SALAGER, 1992; ROMANO; CINCOTTO; PILEGGI, 2018). O uso de AIA, quando não há domínio da técnica, pode aumentar a porosidade do revestimento, bem como diminuir sua resistência mecânica, tornando-o mais propício ainda à percolação de umidade e às patologias associadas (ROMANO, 2013). Além disso, excesso de aditivo incorporador de ar, segundo Mehta e Monteiro (1994), pode causar retardamento excessivo na hidratação do cimento, uma vez que as moléculas dos tensoativos se unem às partículas de cimento por sua parte polar (atração por cargas opostas), ficando a cauda apolar voltada para a água. Assim, forma-se uma camada de tensoativos ao redor das partículas de cimento que repele a água e pode retardar as reações de hidratação, a depender da quantidade de aditivo empregada.

Já os AEH são substâncias compostas de uma solução aquosa de sais ácidos hidrocarboxilados e carboidratos, considerados agentes ativos de superfície (CHAPPUIS et al., 1991; RAMACHANDRAN et $a l .$, 2002). Esses aditivos são uma variação dos retardadores, utilizados para prorrogar o início das reações do cimento por tempo prolongado, uma vez que atuam sobre todos os minerais do clínquer, promovendo redução da quantidade de sulfato de cálcio de solução, o que inibe a nucleação e a formação de silicato de cálcio hidratado (PAOLINI; KHURANA, 1998). Assim, formam uma película hidrorrepelente ao redor dos grãos que impede que se hidratem até que essa barreira seja rompida (PAOLINI; KHURANA, 1998; MEHTA; MONTEIRO, 2014), aumentando, assim, o período de indução e alterando a taxa de hidratação dos compostos (CHEUNG et al., 2011) e, consequentemente, os tempos de pega. Segundo Couto (2011), quando utilizado em quantidade excessiva, o AEH também pode reduzir significativamente a resistência da argamassa.

Esses aditivos podem afetar, além da reologia da mistura, as propriedades endurecidas da argamassa. Além disso, a depender das quantidades empregadas, pode haver prejuízo em algumas propriedades, assim como inversão de função (GARCIA; OLIVEIRA; PANDOLFELLI, 2007) e sobreposição de efeitos de um aditivo sobre o outro.

Grande parte do emprego das argamassas estabilizadas tem sido em revestimentos argamassados, os quais, ainda que executados com argamassa convencional, com normatização e propriedades conhecidas, são alvos de diversas patologias, especialmente vinculadas à umidade. Manchas, mofo, bolor, eflorescência e desplacamentos são exemplos típicos e perceptíveis em fachadas. As argamassas estabilizadas, se não bem empregadas, podem acabar piorando esse cenário, visto que existe uma ampla faixa de variabilidade nas propriedades entre os diferentes lotes fornecidos pelos fabricantes de argamassas, o que demonstra potencial instabilidade do produto.

Assim, as pesquisas que envolvem argamassas estabilizadas vêm aumentando no sentido de melhor compreender as propriedades e os fenômenos envolvidos. Como exemplos há os estudos de Casali et al. (2011), Thomé et al. (2019), Bellei e Caten (2019) e Silva et al. (2019), que avaliaram a influência da forma de armazenamento das argamassas estabilizadas em suas propriedades, já que os fabricantes indicam uma lâmina d'água de $2 \mathrm{~cm}$ sobre a mistura durante o período de estabilização, a qual deve ser removida antes da utilização. Os autores constataram que a lâmina d'água durante o armazenamento exerce influência sobre as propriedades ensaiadas, conservando melhor as condições de trabalhabilidade ao longo do tempo, porém podem alterar a resistência mecânica e a permeabilidade devido à alteração da relação água-cimento. As 
condições de cura das argamassas estabilizadas foram avaliadas por Karkotli et al. (2019) e Melo et al. (2019), chegando-se a resultados que indicam que a umidade favorece o ganho de resistência dessas argamassas. Barcelos e Pelisser (2011), Pagnussat, Vidor e Masuero (2012), Roque e Polesello (2019) e Duarte et al. (2019) estudaram as propriedades das argamassas estabilizadas ao longo do período de estabilização e constataram diminuição na resistência mecânica das misturas com o aumento do tempo de estabilização decorrido antes de serem moldados os corpos de prova, contrariamente ao que foi obtido por Pinheiro et al. (2019). Guindani e Rocha (2019) e Santana, Pereira e Silva (2019) avaliaram as propriedades das argamassas estabilizadas com substituições parciais do agregado miúdo. Guindani e Rocha (2019) utilizaram substituições com fíler basalto, cinza volante e fíler de quartzo, em que constataram que o fíler de quartzo apresentou a melhor conservação da fluidez da mistura, porém sem contribuição para a redução da exsudação. Já o fíler basáltico causou maior redução na fluidez, porém gerou menores exsudações. Já Santana, Pereira e Silva (2019) substituíram o agregado natural por agregado reciclado em 0\%, 25\%, 50\% e $100 \%$, tendo verificado que não ocorreram alterações significativas no estado fresco das argamassas em comparação à argamassa de referência, enquanto no estado endurecido houve redução das propriedades mecânicas com o aumento do teor da substituição.

Avaliando a ação isolada e conjunta dos aditivos AEH e AIA sobre as argamassas, Bauer e Oliveira (2017) investigaram formulações variando os teores dos aditivos e o traço das misturas, buscando atender aos quesitos técnicos de argamassa de revestimento. Os resultados mostraram que o $\mathrm{AEH}$ isolado não influenciou no teor de ar incorporado, proporcionando redução da resistência mecânica e aumento na capilaridade à medida que se aumentam os teores do aditivo. Já o emprego só do AIA elevou o teor de ar incorporado proporcionalmente aos incrementos no teor do aditivo, sendo esse efeito potencializado quando associado ao AEH, promovendo redução da água. O AIA não prejudicou as propriedades mecânicas quando aplicado sozinho e, quando em conjunto com AEH, reduziu ainda mais a capilaridade das argamassas. No entanto, houve alteração da quantidade de água nesse trabalho a fim de se manter constante a consistência, devendo ser considerado esse fator na análise dos resultados.

A influência do tipo de cimento e da quantidade de água nas propriedades do estado fresco de argamassas estabilizadas foi pesquisada por Casali et al. (2018), que avaliaram misturas nas idades de 0h, 24h e 48h. As propriedades reológicas demonstraram sofrer influência do tempo de estabilização e do tipo de cimento empregado, isto é, a proporção água-materiais secos influenciou de forma significativa o teor de ar incorporado, o que não foi observado para os tipos de cimento e para o tempo de estabilização. O índice de consistência se mostrou maior quanto mais alta a relação água-materiais secos. O deslocamento máximo obtido no ensaio squeeze-flow demonstrou ter correlação direta com o teor de ar incorporado e inversa quanto à relação água-materiais secos.

Percebe-se que são muitas as variáveis envolvidas no estudo de argamassas estabilizadas, as quais vêm sendo progressivamente exploradas, porém ainda com poucas evidências científicas. Devido à grande variabilidade entre lotes distintos de mesma argamassa e à falta de normalizações específicas para nortear a produção, a aplicação e o controle tecnológico, torna-se difícil traçar uma padronização dessas misturas por parte dos fabricantes. Assim, esta pesquisa teve como objetivo avaliar a ação isolada e conjunta dos aditivos incorporadores de ar e estabilizadores de hidratação em pastas de cimento Portland, desprezando-se, assim, o efeito do agregado miúdo. Dessa forma, pretende-se contribuir para um maior entendimento da ação desses aditivos sobre as partículas de cimento e dos efeitos combinados entre os aditivos.

\section{Estudo da pasta estabilizada}

O estudo das propriedades da pasta de cimento estabilizada constitui um importante passo para a compreensão da composição e do desempenho da argamassa estabilizada. A pasta proporciona fluidez e coesão à argamassa, de forma que as propriedades reológicas dependem invariavelmente de suas características.

Conforme Clasen e Kulicke (2001), são muitos os fatores que podem influenciar nas características reológicas da pasta de cimento, como relação água-cimento; características do cimento como finura, área superficial, composição e processo de hidratação; natureza das adições químicas e minerais incorporadas à mistura; procedimento de mistura utilizado em sua produção; e idade da pasta. Além disso, as condições de ensaio e ambientais durante as determinações, como a temperatura e a umidade, também podem exercer influência no comportamento das pastas de cimento fresca, no processo de cura e nas propriedades endurecidas.

Segundo Oliveira (2013), a seleção de aditivos químicos e adições minerais por meio de ensaios somente 
com pasta de cimento parece ser uma alternativa, pois estes afetam principalmente o comportamento do escoamento do fluxo da pasta de cimento, interagindo diretamente com a trabalhabilidade, sem qualquer alteração da composição ou efeitos produzidos pelos agregados. Em pastas, como não há a presença do agregado, as microbolhas de ar incorporadas devido à introdução do AIA tendem a aumentar a estruturação do sistema, tornando as misturas mais viscosas devido ao efeito ponte entre as partículas de cimento e as moléculas do aditivo (RIXON; MAILVAGANAN, 1999; WHITING; NAGI, 1998; ANTUNES, 2005). Em argamassas esses efeitos também existem, porém predomina o que chamam de rolamento, quando as bolhas de ar incorporadas funcionam como microesferas compressíveis, diminuindo o atrito entre os grãos de agregado e melhorando o rolamento entre as partículas (ROMANO, 2013).

A relação entre a reologia da pasta de cimento e a reologia da argamassa nem sempre pode ser bem estabelecida, uma vez que os parâmetros reológicos medidos poderão ser distintos. Mesmo assim, as propriedades de escoamento da pasta de cimento, se medidas adequadamente, podem ser usadas para controlar a utilização dos aditivos químicos e das adições minerais (FERRARIS; OBLA; HILL, 2001).

Os tempos de pega das pastas estabilizadas são fatores importantes a serem considerados, uma vez que as argamassas estabilizadas são comercializadas com o intuito de retardar o início das reações, objetivando um manuseio prolongado. Esses tempos dependem, entre outros fatores, da quantidade de aditivos utilizada, os quais atuam diretamente sobre as partículas de cimento, alterando as taxas de hidratação dos compostos anidros e a formação dos produtos cristalinos. O processo de hidratação do cimento anidro se dá por meio de reações químicas, as quais ocorrem em diferentes taxas entre os minerais do clínquer, as diferentes formas de sulfato de cálcio, a cal livre, os álcalis e a água, exercendo influência um sobre o outro. Os produtos gerados nessa reação provocam mudanças físico-mecânicas no sistema, as quais implicarão a pega e o endurecimento dele (TAYLOR, 1990; SOUZA, 2007).

\section{Materiais e métodos}

Os materiais utilizados na pesquisa foram escolhidos de acordo com o empregado em uma empresa de argamassa estabilizada atuante na região Sul. O cimento empregado foi o CP II-F 40, e suas características se encontram na Tabela 1. Foram utilizados um aditivo incorporador de ar (AIA) e um aditivo estabilizador de hidratação (AEH), conforme características técnicas contidas na Tabela 2.

Foram analisadas ao total nove pastas de cimento Portland, com a mesma relação água-aglomerante de 0,4 , variando-se os teores de $\operatorname{AIA}(0,00 \%, 0,30 \%$ e $0,50 \%)$ e $\mathrm{AEH}(0,00 \%, 0,75 \%$ e $1,50 \%)$, em relação à massa de cimento, conforme apresenta a Tabela 3. Os teores de aditivos foram estabelecidos com base nos valores utilizados pelas empresas fornecedoras de argamassas da região Sul.

Tabela 1 - Características químicas, físicas e mecânicas do cimento CPII F-40

\begin{tabular}{|c|c|c|c|c|}
\hline \multicolumn{2}{|c|}{ Ensaio } & $\begin{array}{l}\text { Dados do } \\
\text { cimento }\end{array}$ & $\begin{array}{c}\text { Limite de } \\
\text { norma }\end{array}$ & Normativa \\
\hline \multicolumn{5}{|c|}{ Ensaios Químicos } \\
\hline \multicolumn{2}{|c|}{ Perda ao fogo $(\%)$} & 4,71 & $\leq 6,5$ & NM 18 (ABNT, 2012a) \\
\hline \multicolumn{2}{|c|}{ Óxido de magnésio (\%) } & 5,99 & $\leq 6,5$ & NM 14 (ABNT, 2012b) \\
\hline \multicolumn{2}{|c|}{ Anidrido sulfúrico (\%) } & 3,17 & $\leq 4,0$ & NM 16 (ABNT, 2012c) \\
\hline \multicolumn{2}{|c|}{ Resíduo insolúvel (\%) } & 1,08 & $\leq 2,5$ & NM 22 (ABNT, 2012d) \\
\hline \multicolumn{5}{|c|}{ Ensaios Físicos e Mecânicos } \\
\hline \multicolumn{2}{|c|}{ Finura - \#200 (\%) } & 0,38 & $\leq 10,0$ & 11579 (ABNT, 2013) \\
\hline \multicolumn{2}{|c|}{ Água de consistência (\%) } & 29,00 & N/A & \\
\hline \multirow{2}{*}{$\begin{array}{l}\text { Tempo de } \\
\text { pega }\end{array}$} & Início (min) & 319,60 & $\geq 60$ & \multirow{2}{*}{ NBR16607 (ABNT, 2018) } \\
\hline & Fim (min) & 381,54 & $\leq 600$ & \\
\hline \multicolumn{2}{|c|}{$\begin{array}{l}\text { Expansibilidade a quente } \\
(\mathrm{mm})\end{array}$} & 0,45 & $\leq 5,0$ & NBR 11582 (ABNT, 2016) \\
\hline \multirow{4}{*}{$\begin{array}{l}\text { Resistência } \\
\text { à } \\
\text { compressão }\end{array}$} & $1 \mathrm{dia}$ & 25,36 & N/A & \multirow{4}{*}{ NBR 7215 (ABNT, 2019) } \\
\hline & 3 dias & 37,61 & $\geq 15,0$ & \\
\hline & 7 dias & 42,89 & $\geq 25,0$ & \\
\hline & 28 dias & 50,28 & $\geq 40,0$ & \\
\hline \multicolumn{2}{|c|}{ Massa específica $\left(\mathrm{g} / \mathrm{cm}^{3}\right)$} & 3,09 & & NBR 16605 (ABNT, 2017) \\
\hline
\end{tabular}


Tabela 2 - Dados técnicos dos aditivos

\begin{tabular}{l|l|l}
\hline Característica & Aditivo incorporador de ar (AIA) & Aditivo estabilizador de hidratação (AEH) \\
\hline Substância & $\begin{array}{l}\text { Lauril éter sulfato de sódio (C-10/ } \\
\mathrm{C}-16)-50-70 \%\end{array}$ & - \\
\hline Densidade & $0,98-1,20\left(\mathrm{~g} / \mathrm{cm}^{3}\right)$ & $1,15-1,19\left(\mathrm{~g} / \mathrm{cm}^{3}\right)$ \\
\hline Dosagem & $0,1-0,5(\%$ da massa do cimento) & $0,2-1,5(\%$ da massa do cimento) \\
\hline Cor & Amarelo & Marrom claro \\
\hline $\mathrm{pH}$ & $7,00-9,00$ & $5,00-7,00$ \\
\hline Solubilidade & Solúvel em água & Solúvel em água \\
\hline
\end{tabular}

Tabela 3 - Teores de aditivos e denominação das pastas de cimento Portland estudadas

\begin{tabular}{c|c|c|c|c|c|c|c|c|c}
\hline Mistura & E0I0 & E75I0 & E150I0 & E0I30 & E0I50 & E75I30 & E75I50 & E150I30 & E150I50 \\
\hline AEH (\%) & 0,00 & 0,75 & 1,50 & 0,00 & 0,00 & 0,75 & 0,75 & 1,50 & 1,50 \\
\hline AIA (\%) & 0,00 & 0,00 & 0,00 & 0,30 & 0,50 & 0,30 & 0,50 & 0,30 & 0,50 \\
\hline
\end{tabular}

A nomenclatura das pastas é dada pelas letras "E", de estabilizador, e "I", de incorporador, ambas seguidas dos teores dos aditivos empregados em cada mistura. Os procedimentos de misturas das pastas foram sempre constantes. Inicialmente foi colocado todo o material líquido (água mais os aditivos) na cuba da argamassadeira com movimento planetário, deixando-se misturar a uma velocidade baixa durante $20 \mathrm{~s}$ para homogeneização. Aos poucos foram adicionados cimento Portland e misturou-se por mais $60 \mathrm{~s}$ em velocidade baixa. O equipamento foi desligado durante $15 \mathrm{~s}$ para a raspagem das laterais da cuba. Em seguida, o equipamento foi novamente ligado por $120 \mathrm{~s}$ em velocidade alta.

Para as pastas no estado fresco foram avaliadas a densidade de massa, o teor de ar incorporado (ABNT, 2005a), a viscosidade (viscosímetro Brookfield) e o tempo de início de pega (calorimetria semiadiabática), avaliando-se três amostras de cada mistura. No estado endurecido avaliaram-se o coeficiente de capilaridade (ABNT, 2005b), a resistência à tração e à compressão (ABNT, 2005c), e a densidade de massa aparente (ABNT, 2005d). Assim, foram ensaiados três corpos de prova prismáticos $(4 \times 4 \times 16 \mathrm{~cm})$, seguindo-se os procedimentos prescritos para ', conforme normativas citadas.

Para a realização do ensaio de viscosidade no viscosímetro Brookfield, foram padronizados $25 \mathrm{rpm}$ e o spindle de número 29, o qual submergiu em amostras de $25 \mathrm{~g}$ de pasta de cimento Portland. A fim de se reduzir a componente inercial do ensaio, foi calculada a viscosidade cinemática $\left(\mathrm{m}^{2} / \mathrm{s}\right)$ das pastas, razão entre a viscosidade aparente medida em Pascal vezes segundo (Pa.s) e a densidade de massa $\left(\mathrm{g} / \mathrm{cm}^{3}\right)$ de cada amostra. Para tanto, foram realizadas leituras nos períodos de $0 \mathrm{~s}, 300 \mathrm{~s}, 600 \mathrm{~s}$ e $900 \mathrm{~s}$. Após cada intervalo de tempo entre 0s e 900s, o aparelho era desligado e a mistura permanecia em repouso até a próxima leitura. Após a última leitura (900s), o equipamento ficou constantemente ligado e foram realizadas medições aos $1.200 \mathrm{~s}, 1.380 \mathrm{~s}$ e $1.560 \mathrm{~s}$.

O método utilizado para a determinação do tempo de início de pega das pastas foi o do calorímetro semiadiabático, o qual fez associação entre os tempos de pega e as curvas de evolução de temperaturas devido às reações de hidratação do cimento monitorados ao longo de $48 \mathrm{~h}$. As medições foram programadas para registro a cada minuto. Foram avaliadas três amostras por pasta. A análise dos gráficos para estimativa do tempo de início de pega foi realizada pelo método das tangentes. Pelo gráfico de temperatura versus tempo, foi obtido o tempo de início de pega da pasta mediante o cruzamento entre uma reta horizontal, tangenciando a temperatura mínima atingida, e uma reta inclinada, tangenciando a curva de aceleração.

A análise dos dados foi realizada no programa SPSS (Statistical Package for Social Sciences, versão 20.0). A normalidade de distribuição foi verificada com o teste de Shapiro-Wilk. Os resultados entre as diferentes pastas foram comparados por meio dos testes estatísticos ANOVA e Post Hoc de Tukey $(p<0,05)$. Na análise de dados, considera-se que existe diferença estatisticamente significativa entre os resultados quando $\mathrm{p}<0,05$, caso contrário se considera que não existem diferenças. No caso de haver diferenças $(\mathrm{p}<0,05)$, aplicou-se o Teste Post Hoc de Tukey para avaliar quais grupos são diferentes e quais são semelhantes, sendo empregadas letras sobrescritas para a identificação. Quando os resultados recebem letras sobrescritas iguais,é indicação de que entre eles não existem diferenças, e quando recebem letras diferentes, significa que são estatisticamente diferentes. 


\section{Resultados e discussões}

Os resultados do teor de ar incorporado, densidade de massa e coeficiente de capilaridade são apresentados na Figura 1 para as nove pastas de cimento Portland.

Percebe-se que, quanto à densidade de massa, foram obtidos valores muito próximos a $1,8 \mathrm{~g} / \mathrm{cm}^{3}$ para quase todas as pastas, com exceção de E0I0 $\left(1,84 \mathrm{~g} / \mathrm{cm}^{3}\right)$ e E75I50 $\left(1,75 \mathrm{~g} / \mathrm{cm}^{3}\right)$. Com relação ao teor de ar incorporado, não foram verificadas diferenças significativas entre as pastas ( $>>0,05)$, obtendo-se um valor médio de ar incorporado de 6\%. As amostras E75I0 e E150I0, com somente AEH, também ficaram próximas ao valor médio obtido, não apresentando diferenças significativas. A exceção foi verificada nas misturas E0I0 e E75I50, em que foram obtidos valores de ar incorporado de 4,21\% e 8,25\% respectivamente, valores estatisticamente diferentes dos demais $(\mathrm{p}<0,05)$.

A pasta E75I50 (0,75\% de AEH e 0,50\% de AIA) incorporou 1,95\% a mais de ar do que a pasta E150I50 ( $1,50 \%$ de AEH e $0,50 \%$ de AIA) e $2,43 \%$ a mais do que a pasta E75I30 (0,75\% de AEH e 0,30\% de AIA). Já quando comparado à E0I50 (0,00\% de AEH e 0,50\% de AIA), E75I50 apresentou 1,65\% a mais de ar na pasta, o que poderia estar associado à parcela de incorporação por parte do AEH. Analisando as demais pastas com aditivos combinados (AEH e AIA), observou-se que não ocorreram efeitos que pudessem ser somados, quando comparados com pastas com apenas um tipo de aditivo. É importante ressaltar a diferença da análise da incorporação de ar em pastas e em argamassas, uma vez que a presença do agregado altera as condições de ancoragem das micelas formadas pelas moléculas de aditivo incorporador de ar (ROMANO, 2013).

O coeficiente de capilaridade apresentou valores mais distintos entre as pastas estudadas, sendo os resultados para E0I0, E0I30 e E150I50 semelhantes entre si $(\mathrm{p}>0,05)$ e próximos a 3,0g/dm². $\mathrm{min}^{1 / 2}$, enquanto as demais pastas tiveram resultados distintos $(\mathrm{p}<0,05)$. Nas pastas somente com AEH (E75I0 e E150I0) foram encontrados coeficientes de capilaridade bastante superiores aos obtidos nas pastas somente com aditivo AIA (E0I30 e E0I50). Bauer e Oliveira (2017) também encontraram resultados similares quanto à capilaridade de argamassas com aditivos isolados, em que as misturas com AEH apresentaram coeficiente de capilaridade bastante superior ao das misturas com AIA. Porém, nas pastas com aditivos combinados (E75I30, E75I50, E150I30 e E150I50) foi observada a tendência de que, para um mesmo teor de AEH, aumentando-se o teor de AIA, a capilaridade diminuiu. Para a mistura E0I0, em que foi obtido o menor teor de ar incorporado $(4,21 \%)$, encontrou-se o menor coeficiente de capilaridade $\left(2,73 \mathrm{~g} / \mathrm{dm}^{2} \cdot \mathrm{min}^{1 / 2}\right)$. Comparando-se as demais pastas com E0I0, percebe-se que todas possuem maior teor de ar incorporado e, ao mesmo tempo, maior coeficiente de capilaridade. Logo, neste estudo em pastas, nem sempre foi verificada a teoria de que a absorção capilar é reduzida pela presença de bolhas de ar por interromperem a passagem de líquidos pelos canais capilares (RAMACHANDRAN, 1984). A capilaridade apresentou-se maior nas pastas que receberam somente $\mathrm{AEH}$ e, entre as pastas com aditivos combinados, naquelas com menor teor de AIA.

Analisando o coeficiente de capilaridade em relação à densidade de massa no estado endurecido, em uma análise geral, observa-se pela Figura 2 uma boa correlação $\left(\mathrm{R}^{2}=0,7056\right)$ obtida, demonstrando que, quanto mais densa for a estrutura da pasta endurecida, menor será a percolação de água pelos capilares. Assim, percebe-se que a capilaridade tem correlação com a densidade endurecida da pasta, porém esse potencial capilar irá depender, entre outros fatores, das características dos poros dessa estrutura, como o raio, a tortuosidade e a conectividade (ALVES, 2002).

A tensão de escoamento das pastas é apresentada na Figura 3, juntamente com os teores de AEH e AIA empregados em cada mistura. Pelo gráfico consegue-se perceber na análise das misturas com aditivos isolados que o AEH tende a diminuir a tensão de escoamento das pastas, enquanto o AIA proporciona o aumento dessa tensão. Isso ocorre porque o AIA promove maior estruturação interna devido ao efeito ponte entre suas moléculas e as partículas de cimento, enquanto o $\mathrm{AEH}$ tem um caráter dispersante, proporcionando maior quantidade de água livre inicial à mistura devido ao retardo das reações de hidratação.

A Figura 4 ilustra essa tendência proporcionada por cada aditivo através de um gráfico com a tensão de escoamento das pastas expressas em relação a E0I0 (referência). Assim, foi atribuído o valor de 1,00 para a tensão de escoamento de E0I0 (referência), estando as demais tensões das pastas relativas a essa.

E0I50 (0,00\% de AEH e 0,50\% AIA) foi a mistura com maior tensão de escoamento, com valor 50\% maior que E0I0. Na sequência apareceram E75I30 (0,75\% de AEH e 0,3\% de AIA) e E0I30 (0,00\% de AEH e $0,30 \%$ de AIA), também com tensões superiores a E0I0. As demais pastas com a combinação de ambos os aditivos (E75I50, E150I30 e E150I50) tiveram tensões de escoamento aproximadas entre si, inferiores a 
E0I0, sendo menores $\left(75 \mathrm{~d} / \mathrm{cm}^{2}\right)$ para o teor máximo de 1,50\% de AEH (E150I30 e E150I50). As menores tensões de escoamento foram obtidas para E75I0 e E150I0, apenas com AEH.

Os resultados quanto à viscosidade cinemática das pastas ao longo do tempo de $1.560 \mathrm{~s}$ são apresentados na Figura 5. As pastas E150I0, E0I50, E75I30, E150I30 e E150I50 apresentaram comportamentos similares quanto à viscosidade cinemática, com medidas crescentes ao longo de todo o ensaio, isto é, quanto maior o tempo em aberto das pastas, maior a resistência ao fluxo, o que também foi observado em E0I0, E75I0 E0I30 e E75I50, porém com uma elevação mais brusca de viscosidade após o viscosímetro permanecer constantemente ligado, ultrapassando $200 \%$ da viscosidade inicial para E0I0 e E75I0.

Figura 1 - Teor de ar incorporado, densidade de massa no estado fresco e coeficiente de capilaridade

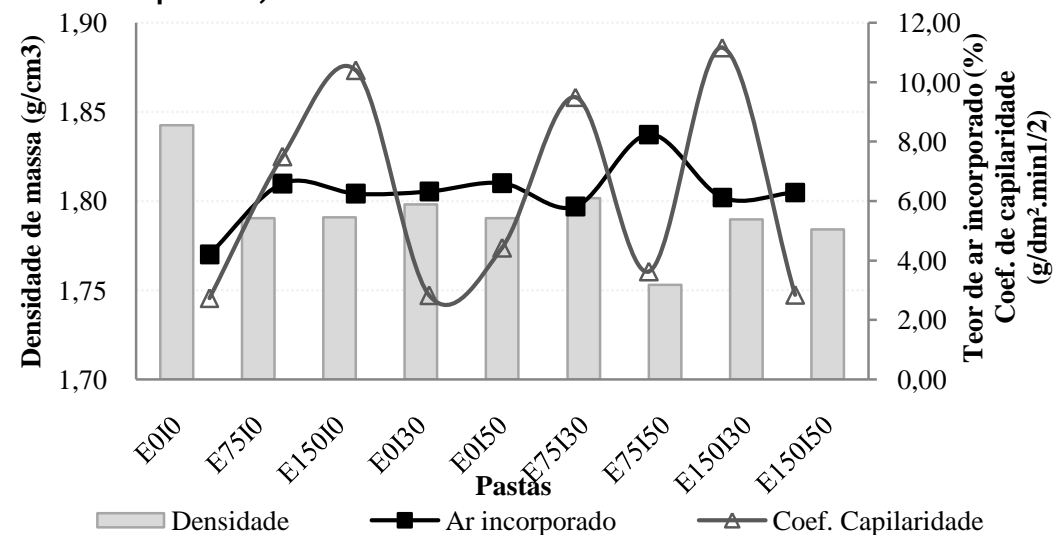

Figura 2 - Correlação entre o coeficiente de capilaridade e a densidade de massa no estado endurecido das pastas

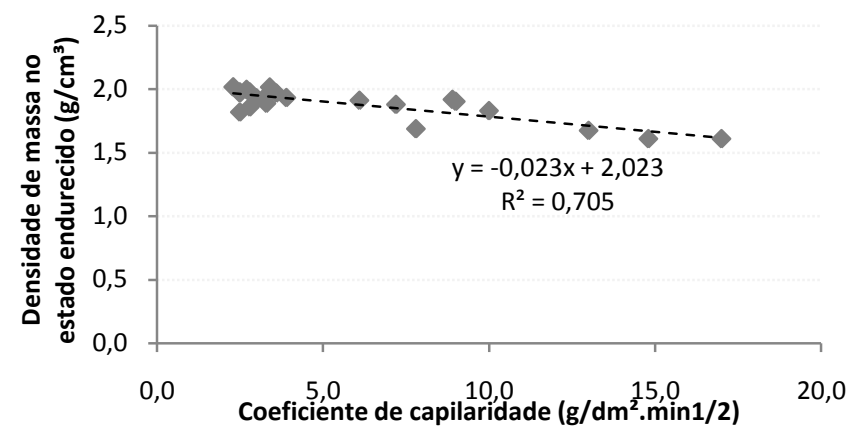

Figura 3 - Tensão de escoamento das pastas e respectivos teores de aditivos empregados

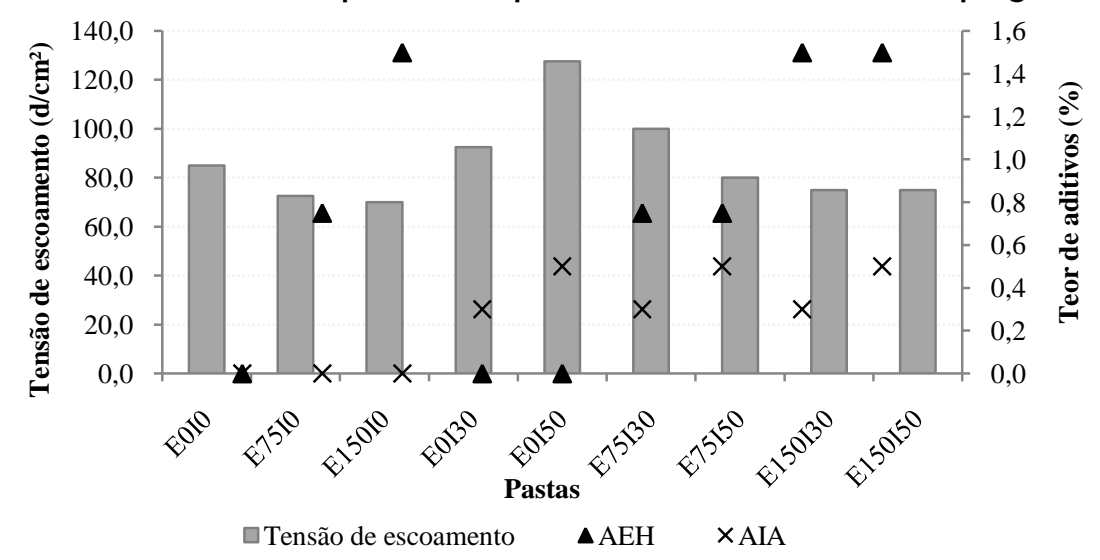


Figura 4 - Tensão de escoamento relativa das pastas (proporção de E0I0), de acordo com os teores de aditivos

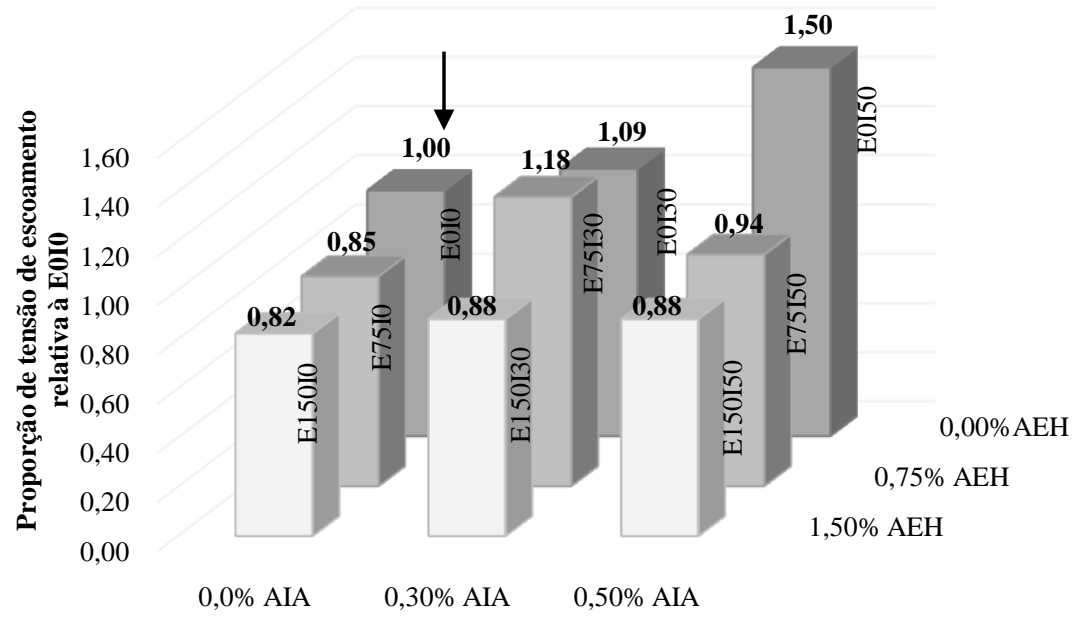

Figura 5 - Viscosidade das pastas de cimento

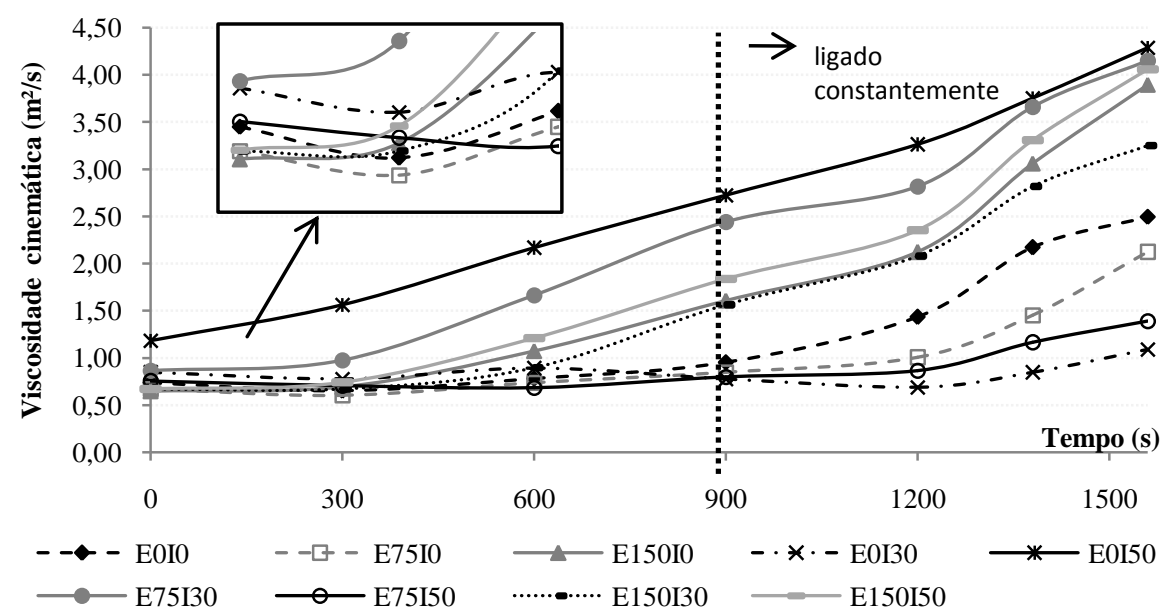

A pasta E75I50 com maior teor de incorporação de ar ficou entre as pastas menos viscosas ao longo do ensaio, indo contra a teoria que afirma que em pastas ocorre ganho de consistência com o aumento do teor de ar incorporado, devido ao efeito ponte com as partículas de cimento (WHITING; NAGI, 1998; RIXON; MAILVAGANAM, 1999). Nesse caso, o resultado poderia estar vinculado ao efeito dispersante do AEH empregado na mistura. $\mathrm{O}$ que se pode perceber é que a pasta com comportamento mais viscoso ao longo de todo o ensaio foi a E0I50, mistura com apenas aditivo AIA no maior teor estudado $(0,50 \%)$, indicando que esse aumento de viscosidade devido ao efeito ponte pode estar vinculado à quantidade de AIA empregada, e não à quantidade de ar incorporado. Ao mesmo tempo, mesmo ficando entre as maiores tensões de escoamento, a pasta E0I30, que recebeu $0,30 \%$ de AIA, se mostrou a menos viscosa ao longo do tempo de ensaio.

Conforme o estudado, ambos os aditivos incorporaram ar às pastas, porém, possivelmente, as bolhas incorporadas por cada um não possuam a mesma estabilidade, uma vez que o AIA carrega eletrostaticamente as bolhas de ar com mesma carga, gerando repulsão e diminuindo a tendência de coalescência, diferentemente das bolhas sem o aditivo AIA (ROMANO, 2013; SANTOS; DE LIMA; GOMES, 2017). A rotação do spindle imerso na pasta ao ser submetida ao ensaio de viscosidade promove um fluxo em seu entorno, que pode fazer com que as bolhas de ar instáveis entrem em colapso, proporcionando alterações na viscosidade.

As curvas de monitoramento de temperatura ao longo de $48 \mathrm{~h}$ para as nove pastas de cimento Portland estudadas são apresentadas na Figura 6. Ao observar a Figura 6, têm-se a curva de elevação de temperaturas 
das pastas E0I0, E0I30 e E0I50, a qual não ocorreu nas demais pastas durante o período monitorado, sendo possivelmente superior a $48 \mathrm{~h}$ devido à ação de retardo de pega proporcionado pelo aditivo AEH sobre todos os minerais de clínquer (PAOLINI; KHURANA, 1998; MEHTA; MONTEIRO, 2008). Assim, somente foi estimado o tempo de início de pega para as pastas sem o AEH. Pelo método das tangentes, obteve-se tempo de início de pega de 6,5 h para E0I0, enquanto para E0I50 obteve-se um tempo de $11 \mathrm{~h}$, e para E0I30, de 11,5 h. Obteve-se retardo de pega de até $5 \mathrm{~h}$ em relação a E0I0 (mistura de referência), proporcionado apenas pelo AIA, uma vez que E0I30 e E0I50 só possuem esse aditivo. Ao mesmo tempo, esse retardo não demonstrou ser proporcional ao teor de AIA empregado, conforme demonstram as curvas de E0I30 e E0I50. Para uma mesma proporção água-aglomerante, o AIA proporcionou um afastamento maior das partículas de cimento (ROMANO; CINCOTTO; PILEGGI, 2018), o que talvez tenha ocasionado retardo no início das reações.

Na Figura 7 são apresentados os resultados de resistência mecânica e de densidade de massa no estado endurecido aos 28 dias de idade. É possível perceber que as pastas E150I0, E150I30 e E150I50, todas com teor máximo de $1,50 \%$ de $\mathrm{AEH}$, tiveram suas resistências estatisticamente semelhantes entre si $(\mathrm{p}>0,05)$, com valores bem inferiores às demais pastas, o que também foi observado pelas menores densidades de massa obtidas no estado endurecido. Bauer e Oliveira (2017) também obtiveram resistência mecânica das argamassas com teor de $\mathrm{AEH}$ de 1,50\% muito inferior às demais misturas, o que reforça a tendência comportamental encontrada em pastas.

Comparando-se E150I0 com E75I0, o teor de AEH foi duplicado enquanto a resistência à compressão atingiu aproximadamente $10 \%$ e a resistência à tração $28 \%$ dos valores de resistências obtidos na amostra E75I0. Essa alta dosagem de aditivo possivelmente tenha influenciado o processo de hidratação do cimento, podendo ter retardado também as propriedades no estado endurecido das pastas. As pastas E0I0 e E75I0 atingiram as maiores resistências à compressão, próximas a 44MPa. As pastas E75I30 e E75I50 foram as que atingiram as maiores resistências à tração. Já na resistência à compressão, a mistura E75I50 apresentou valor 23\% maior que E75I30, mesmo com maior teor de AIA. Analisando E0I30 e E0I50, em comparação com E0I0, as resistências à compressão ficaram muito próximas entre si, alcançando quase 90\% de E0I0, o que, estatisticamente, foi considerado igual $(\mathrm{p}>0,05)$. Já as resistências à tração ficaram em torno de $40 \%$ maiores que E0I0, demonstrando que o AIA, nos teores utilizados, não prejudicou as pastas quanto à resistência.

A Figura 8 apresenta uma correlação entre os resultados de resistência à compressão e a densidade de massa no estado endurecido para as nove pastas estudadas. Foi obtido um coeficiente de correlação $\left(\mathrm{R}^{2}\right)$ de 0,89 entre a resistência à compressão e a densidade de massa no estado endurecido, como mostra a Figura 5, demonstrando que a resistência mecânica tem relação com a porosidade e com a formação dos compostos hidratados do cimento.

Figura 6 - Curvas de evolução de temperaturas das pastas ao longo de $48 \mathrm{~h}$

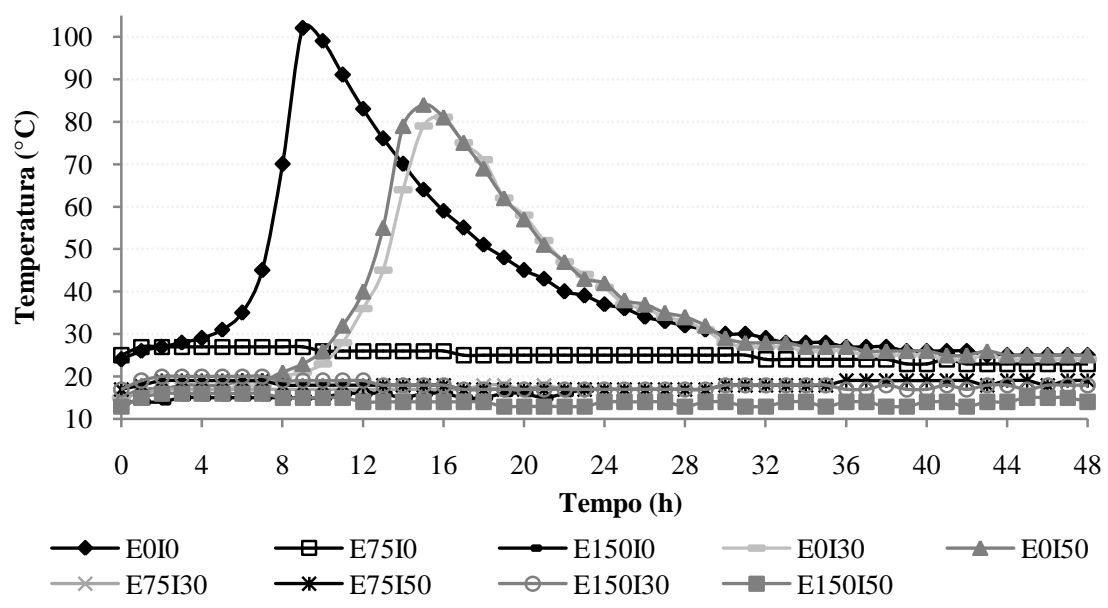


Figura 7 - Resistência mecânica versus densidade de massa no estado endurecido (28 dias)

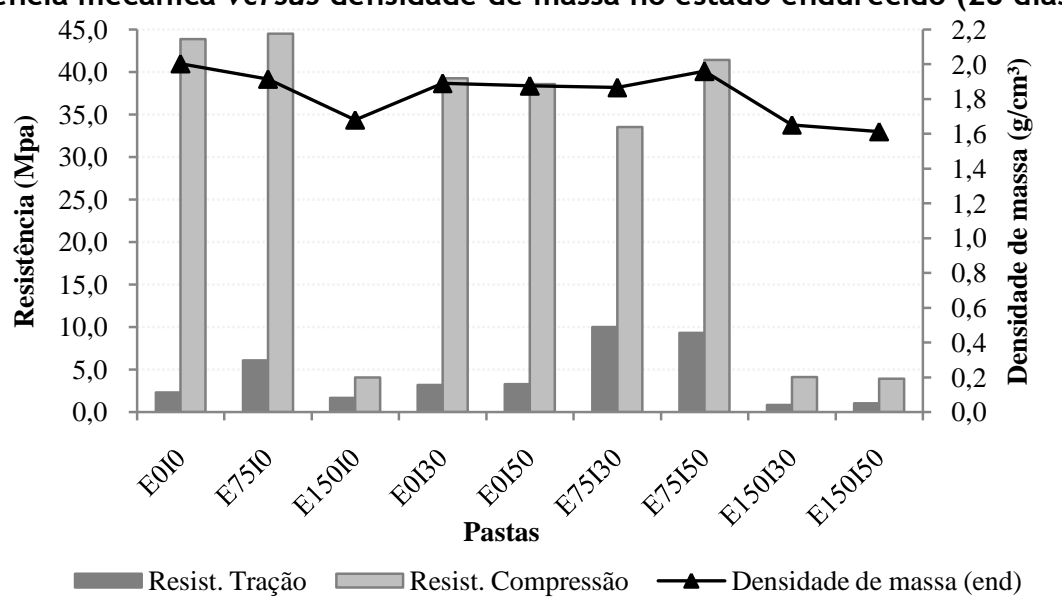

Figura 8 - Correlação entre a resistência à compressão e a densidade de massa no estado endurecido

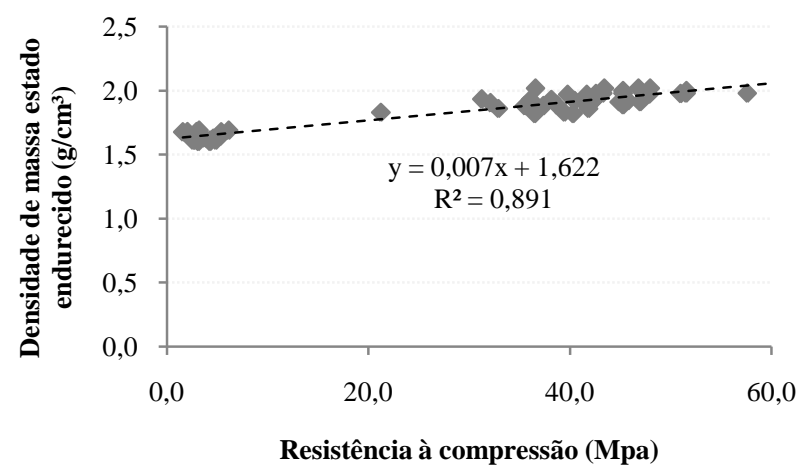

\section{Conclusão}

Como conclusão deste trabalho pode-se inferir que:

(a) os resultados de teor de ar incorporado reforçaram a hipótese de que existe um ponto de saturação das moléculas dos aditivos a partir do qual os efeitos já não são significativos, isto é, mesmo aumentando o teor de AIA, o teor de ar incorporado permanece constante. Foi observado nesta pesquisa que o AEH também é responsável por uma parcela de incorporação de ar nas pastas, porém, quando combinado ao AIA, o efeito observado não foi proporcionalmente acumulativo;

(b) os resultados dos ensaios de capilaridade sugerem que o uso do AEH possivelmente proporcione maior fluxo por capilares, efeito esse reduzido pelo uso do AIA. Fazendo um comparativo com o teor de ar incorporado, o comportamento apresentado pelas pastas indicou que a capilaridade possa estar mais ligada às características das bolhas incorporadas do que à quantidade de ar propriamente dita. $\mathrm{O}$ coeficiente de capilaridade demonstrou boa correlação com a densidade de massa no estado endurecido, sendo maior quanto menores os valores de densidade da pasta;

(c) a tensão de escoamento das pastas demonstrou tendência de aumento com a introdução de AIA, numa relação direta com o teor empregado, e de diminuição com o emprego de AEH, quando utilizados isoladamente;

(d) a viscosidade das pastas ao longo do tempo indicou possíveis correlações com o teor de AIA empregado e com a estabilidade das bolhas incorporadas, e não com o teor de ar incorporado;

(e) pelos resultados obtidos na calorimetria, pode-se identificar um retardo de até $5 \mathrm{~h}$ nos tempos de pega causado pela presença do AIA nas pastas, não demonstrando proporcionalidade com o teor de aditivo empregado. Para as pastas aditivadas com AEH, o tempo de início de pega foi superior a $48 \mathrm{~h}$ (tempo de monitoramento); 
(f) o uso do AEH, quando em teores moderados, elevou a resistência à tração das pastas. Já quando empregado em altos teores, diminuiu tanto a resistência à tração quanto à compressão, indicando possível retardo também na formação dos compostos hidratados. Já o emprego do AIA demonstrou reduzir a resistência à compressão das pastas, porém nos teores empregados na pesquisa essa redução não foi significativa. Cabe ressaltar que as pastas podem ter um comportamento distinto das argamassas, uma vez que a presença do agregado pode influenciar diretamente nas propriedades estudadas; $\mathrm{e}$

(g) os resultados dessa pesquisa indicaram que os teores intermediários de AEH $(0,75 \%)$ demostram ser mais adequados para misturas estabilizadas de cimento Portland, podendo ser associados a teores mais elevados de AIA $(0,50 \%)$ sem comprometer as principais propriedades avaliadas.

\section{Referências}

ALVES, N. J. D. Avaliação dos aditivos incorporadores de ar em argamassas de revestimento. Brasília, 2002. Dissertação (Mestrado em Engenharia Civil) - Faculdade de Tecnologia, Universidade de Brasília, Brasília, 2002.

ANTUNES, R. P. N. Influência da reologia e da energia de impacto na resistência de aderência de revestimentos de argamassa. São Paulo, 2005. Tese (Doutorado em Engenharia Civil) - Escola Politécnica, Universidade de São Paulo, São Paulo, 2005.

ASSOCIAÇÃO BRASILEIRA DE NORMAS TÉCNICAS. NBR 11579: cimento Portland: determinação do índice de finura por meio da peneira $75 \mu \mathrm{m}\left(\mathrm{n}^{\circ} 200\right)$. Rio de Janeiro, 2013.

ASSOCIAÇÃO BRASILEIRA DE NORMAS TÉCNICAS. NBR 11582: cimento Portland: determinação da expansibilidade Le Chatelier. Rio de Janeiro, 2016.

ASSOCIAÇÃO BRASILEIRA DE NORMAS TÉCNICAS. NBR 13278: argamassa para assentamento e revestimento de paredes e tetos: determinação da densidade de massa e do teor de ar incorporado. Rio de Janeiro, 2005a.

ASSOCIAÇÃO BRASILEIRA DE NORMAS TÉCNICAS. NBR 13279: argamassa para assentamento e revestimento de paredes e tetos: determinação da resistência à tração na flexão e à compressão. Rio de Janeiro, 2005c.

ASSOCIAÇÃO BRASILEIRA DE NORMAS TÉCNICAS. NBR 13280: argamassa para assentamento e revestimento de paredes e tetos: determinação da densidade de massa aparente no estado endurecido. Rio de Janeiro, 2005d.

ASSOCIAÇÃO BRASILEIRA DE NORMAS TÉCNICAS. NBR 15259: argamassa para assentamento e revestimento de paredes e tetos: determinação da absorção de água por capilaridade e do coeficiente de capilaridade. Rio de Janeiro, 2005b.

ASSOCIAÇÃO BRASILEIRA DE NORMAS TÉCNICAS. NBR 16605: cimento Portland e outros materiais em pó: determinação da massa específica. Rio de Janeiro, 2017.

ASSOCIAÇÃO BRASILEIRA DE NORMAS TÉCNICAS. NBR 16607: cimento Portland: determinação dos tempos de pega. Rio de Janeiro, 2018.

ASSOCIAÇÃO BRASILEIRA DE NORMAS TÉCNICAS. NBR 7215: cimento Portland: determinação da resistência à compressão de corpos de prova cilíndricos. Rio de Janeiro, 2019.

ASSOCIAÇÃO BRASILEIRA DE NORMAS TÉCNICAS. NBR NM 14: cimento Portland: análise química: método de arbitragem para determinação de dióxido de silício, óxido férrico, óxido de alumínio, óxido de cálcio e óxido de magnésio. Rio de Janeiro, $2012 \mathrm{~b}$.

ASSOCIAÇÃO BRASILEIRA DE NORMAS TÉCNICAS. NBR NM 16: cimento Portland: análise química: determinação de anidrido sulfúrico. Rio de Janeiro, 2012c.

ASSOCIAÇÃO BRASILEIRA DE NORMAS TÉCNICAS. NBR NM 18: cimento Portland: análise química: determinação de perda ao fogo. Rio de Janeiro, 2012a.

ASSOCIAÇÃO BRASILEIRA DE NORMAS TÉCNICAS. NBR NM 22: cimento Portland com adições de materiais pozolânicos: análise química: método de arbitragem. Rio de Janeiro, 2012d. 
BARCELOS, A. S.; PELISSER, F. Efeito de inibidores de hidratação na resistência de aderência à tração em argamassas de revestimento. Artigo técnico de Graduação em Engenharia Civil, UNESC, Criciúma, SC, 2011.

BAUER, E.; OLIVEIRA, V. C. Comportamentos e propriedades das argamassas estabilizadas de revestimentos. In: SIMPÓSIO BRASILEIRO DE TECNOLOGIA DAS ARGAMASSAS, 12., São Paulo, 2017. Anais [...] São Paulo, 2017.

BELLEI, P.; CATEN, A. T. Avaliação do desempenho da argamassa estabilizada de 36 e 72 horas para revestimento externo em diferentes tempos de utilização e modo de armazenamento. In: SIMPÓSIO BRASILEIRO DE TECNOLOGIA DAS ARGAMASSAS, 13., Goiânia, 2019. Anais [...] Goiânia, 2019.

CASALI, J. M. et al. Avaliação das propriedades do estado fresco e endurecido da argamassa estabilizada para assentamento e revestimento. In: SIMPÓSIO BRASILEIRO DE ARGAMASSAS, 9., Belo Horizonte, 2011. Anais [...] Belo Horizonte, 2011.

CASALI, J. M. et al. Influence of cement type and water content on the fresh state properties of ready mix mortar. Ambiente Construído, Porto Alegre, v. 18, n. 2, p. 33-52, abr./jun. 2018.

CHAPPUIS, J. et al. Admixtures and calcium aluminates. Lafarge Aluminates Internal Report, 1991.

CHEUNG, J. et al. Impact of admixtures on the hydration kinetics of portland cement. Cement and Concrete Research, v. 41, n. 12, p. 1289-1309, 2011.

CLASEN, C.; KULICKE, W. M. Determination of viscoelastic and rheo-optical material functions of watersoluble cellulose derivates.Progress in Polymer Science, v. 26, p. 1839-1919, 2001.

COUTO, L. G. Apostila de aditivos. Disciplina de Civ 361 - Materiais de Construção Civil II. Universidade Federal de Viçosa, Departamento de Engenharia Civil: polígrafo didático. Viçosa, Minas Gerais, 2011.

DUARTE, G. L. B. et al. Estudo da trabalhabilidade da argamassa estabilizada ao longo do tempo de armazenamento para assentamento de bloco de concreto. In: SIMPÓSIO BRASILEIRO DE TECNOLOGIA DAS ARGAMASSAS, 13., Goiânia, 2019. Anais [...] Goiânia, 2019.

FERRARIS, C. F.; OBLA, K. H.; HILL, R. The influence of mineral admixtures on the rheology of cement paste and concrete. Cementand Concrete Research, v. 31, n. 2, p. 245-255, 2001.

GARCIA, J. R.; OLIVEIRA, I. R.; PANDOLFELLI, V. C. Processo de hidratação e os mecanismos de atuação dos aditivos aceleradores e retardadores de pega do cimento de aluminato de cálcio. Cerâmica, v. 53, p. 42-56, 2007.

GUINDANI, E. N.; ROCHA, J. C. Adição de finos em argamassas estabilizadas: avaliação das características no estado fresco. In: SIMPÓSIO BRASILEIRO DE TECNOLOGIA DAS ARGAMASSAS, 13., Goiânia, 2019. Anais [...] Goiânia, 2019.

KARKOTLI, L. B. et al. Influência da temperatura e umidade relative do ar na resistência de argamassas estabilizadas. In: SIMPÓSIO BRASILEIRO DE TECNOLOGIA DAS ARGAMASSAS, 13., Goiânia, 2019. Anais [...] Goiânia, 2019.

MEHTA, P. K.; MONTEIRO, P. J. M. Concreto: estrutura, propriedades e materiais. São Paulo: Pini, 1994.

MEHTA, P. K.; MONTEIRO, P. J. M. Concreto: microestrutura, propriedades e materiais. 2. ed. Cidade: Ibracon, 2014.

MELO, F.D. et al. Influência da cura úmida em revestimentos executados em argamassa estabilizada. In: SIMPÓSIO BRASILEIRO DE TECNOLOGIA DAS ARGAMASSAS, 13., Goiânia, 2019. Anais [...] Goiânia, 2019.

OLIVEIRA, C. O. Análise das propriedades reológicas de materiais cimentícios associando o conceito de empacotamento de partículas. Ilha Solteira, 2013. Dissertação (Mestrado em Engenharia Civil) Programa de Pós-Graduação em Engenharia Civil, Universidade Estadual Paulista Júlio de Mesquita Filho, Ilha Solteira, 2013.

PAGNUSSAT, D. T.; VIDOR, D.; MASUERO, A. B. Avaliação de propriedades de argamassas estabilizadas ao longo do seu tempo de utilização. In: CONGRESSO PORTUGUÊS DE ARGAMASSAS E ETICS, 4., Universidade de Coimbra, Coimbra, 2012. Anais [...] Coimbra, 2012. 
PAOLINI, M.; KHURANA, R. Admixtures for recycling of waste concrete. Cementand Concrete Composites, v. 20, p. 221-229, 1998.

PINHEIRO, R. C. et al. Avaliação das propriedades da argamassa estabilizada de 36 horas em diferentes tempos de utilização. In: SIMPÓSIO BRASILEIRO DE TECNOLOGIA DAS ARGAMASSAS, 13., Goiânia, 2019. Anais [...] Goiânia, 2019.

RAMACHANDRAN, V. S. Concrete admixtures handbook. New York: Noyes, 1984.

RAMACHANDRAN, V. S. et al. Handbook of thermal analysis of construction materials. New York: Noyes Publications, 2002.

RIXON, R.; MAILVAGANAM, N. Chemical admixtures for concrete. London: E\&FN SPON, 1999.

ROMANO, R. C. O. Incorporação de ar em materiais cimentícios aplicados em construção civil. São Paulo, 2013. Tese (Doutorado em Engenharia Civil) - Departamento de Engenharia de Construção Civil, Universidade de São Paulo, São Paulo, 2013.

ROMANO, R. C. O.; CINCOTTO, M. A.; PILEGGI, R. G. Incorporação de ar em materiais cimentícios: uma nova abordagem para o desenvolvimento de argamassas de revestimento. Ambiente Construído, Porto Alegre, v. 18, n. 2, p. 289-308, abr./jun. 2018.

ROQUE, D. C.; POLESELLO, E. Análise das propriedades de argamassas estabilizadas para revestimentos em diferentes tempos ao longo do seu período de estabilização. In: SIMPÓSIO BRASILEIRO DE TECNOLOGIA DAS ARGAMASSAS, 13., Goiânia, 2019. Anais [...] Goiânia, 2019.

SALAGER, J. L. El mundo de los surfactantes. Cuaderno FIRP, Universidade de Los Andes: Polígrafo didático. Merida, Venezuela, p. 3-4, 1992.

SANTANA, T. S.; PEREIRA, C. H. A. F.; SILVA, F. G. S. Avaliação de argamassas estabilizadas com agregado reciclado. In: SIMPÓSIO BRASILEIRO DE TECNOLOGIA DAS ARGAMASSAS, 13., Goiânia, 2019. Anais [...] Goiânia, 2019.

SANTOS, H. T.; DE LIMA, F. M.; GOMES, M. F. Estudo das propriedades densidade, estabilidade e resistência à compressão de pasta leve de cimento para poço de petróleo com o uso de incorporador de ar. Revista Eletrônica de Materiais e Processos, v. 12, n. 3, p. 168-173, 2017.

SILVA, L. et al. Estudo das propriedades de argamassas estabilizadas. In: SIMPÓSIO BRASILEIRO DE TECNOLOGIA DAS ARGAMASSAS, 13., Goiânia, 2019. Anais [...] Goiânia, 2019.

SOUZA, A. F. Otimização do uso de aditivo estabilizador de hidratação do cimento em água de lavagem dos caminhões-betoneira para produção de concreto. 2007. 182 f. Dissertação (Mestrado em Engenharia Civil) - Programa de Pós-Graduação em Engenharia Civil, Universidade Federal de Santa Catarina, Florianópolis, 2007.

TAYLOR, H. F. W. Cement chemistry. London: Academic Press, 1990.

THOMÉ, M. W. et al. Estudo da influência da lâmina-d'água utilizada no armazenamento da argamassa estabilizada. In: SIMPÓSIO BRASILEIRO DE TECNOLOGIA DAS ARGAMASSAS, 13., Goiânia, 2019. Anais [...] Goiânia, 2019.

WHITING, D. A.; NAGI, M. A. Manual on control of air content in concrete. 2. ed. Illinois: Portland Cement Association, 1998.

\section{Agradecimentos}

Os autores agradecem à Universidade Federal de Santa Maria (UFSM), pelo apoio, infraestrutura e recursos para a realização da pesquisa, e às empresas Supermix e Supertex, pelo fornecimento dos materiais. 


\author{
Juliana Pippi Antoniazzi \\ Departamento de Expressão Gráfica | Universidade Federal de Santa Maria | Av. Roraima, 1000, Prédio 07 | Santa Maria - RS - Brasil | \\ CEP 97105-900 | Tel.: (55) 3220-8594 | E-mail: juliana.antoniazzi@ufsm.br \\ Gihad Mohamad \\ Departamento de Estruturas e Construção Civil | Universidade Federal de Santa Maria | Tel.: (55) 98142-2533 | E-mail: \\ gihad.civil@gmail.com

\section{Juliana Machado Casali} \\ Departamento Acadêmico de Construção civil | Instituto Federal de Santa Catarina | Av. Mauro Ramos, 950 | Florianópolis - SC - Brasil | \\ CEP 88020-300 | Tel.: (48) 3211-6000 | E-mail: juliana.casali@ifsc.edu.br

\section{Raquel Petry Brondani Schmidt} \\ Departamento de Expressão Gráfica | Universidade Federal de Santa Maria | Tel.: (55) 3220-8594 | E-mail: raquelbrondani@gmail.com

\section{Bernardete Trindade} \\ Departamento de Expressão Gráfica | Universidade Federal de Santa Maria | Tel.: (55) 3220-8146 | E-mail: tbeti@hotmail.com
}

Ambiente Construído

Revista da Associação Nacional de Tecnologia do Ambiente Construído

Av. Osvaldo Aranha, $99-3^{\circ}$ andar, Centro

Porto Alegre - RS - Brasil

CEP $90035-190$

Telefone: +55 (51) 3308-4084

Fax: +55 (51) 3308-4054

www.seer.ufrgs.br/ambienteconstruido

E-mail: ambienteconstruido@ufrgs.br

(c) ()

262 Antoniazzi, J. P.; Mohamad, G.; Casali, J. M.; Schmidt, R. P. B.; Trindade, B. 